\title{
Treatment of Spontaneous Adult Thoracolumbar Spondylodiscitis With Interbody Fusion Using Autogenous Bone from Decorticated Spinous Process Supplanted with Posterolateral Transpedicular Rod-Screw Fixation
}

\author{
MAHMOUD M. WAHDAN, M.D.; MOATAZ A. ELAWADY, M.D. and AHMED M. DEABES, M.D. \\ The Department of Neurosurgery, Faculty of Medicine, Benha University
}

\begin{abstract}
Background: Spontaneous spondylodiscitis, although rare, but carries the risk of developing neurological impairment.

Aim of Study: We aim at introducing our experience with the treatment of spontaneous adult spondylodiscitis with interbody fusion using autogenous bone from decorticated spinous process supplanted with posterolateral transpedicular rod-screw fixation at the Neurosurgery Department of Benha University Hospital between January 2015 and November 2019.

Patients and Methods: Between January 2015 and November 2019, among 51 patients who were diagnosed with pyogenic thoracolumbar spondylodiscitis, 12 patients ( 8 males and 4 females) underwent curettage, drainage and interbody fusion using autogenous bone from the removed spinous process augmented with transpedicular rod-screw fixation.

Results: All patients, but one, showed improvement of their preoperative pain and the level of inflammatory markers in the blood. This patient was diagnosed as having screw pullout and needed surgical reinsertion with a larger screw.

Conclusions: Lumbar interbody fusion using autogenous bone from decorticated spinous process supplanted with posterolateral transpedicular rod-screw fixation represents a reasonable substitute to the traditional anterior curettage, stabilization with additional posterior rod-screw fixation for the treatment of spontaneous lumbar spondylodiscitis.
\end{abstract}

Key Words: Spondylodiscitis - Lumbar interbody fusion Autogenous bone graft.

\section{Introduction}

SPONTANEOUS spondylodiscitis, although rare, but carries the risk of developing neurological impairment [1]

Operative treatment is indicated in cases of poor response to conservative treatment, progres-

Correspondence to: Dr. Mahmoud M. Wahdan,

The Department of Neurosurgery, Faculty of Medicine,

Benha University sive neurologic impairment, spinal instability, or progressive bone degeneration $[2,3]$. It had been traditionally surgically treated via the ordinary approach for curettage and stabilization with additional posterolateral rod/screw fixation [4].

However, a minimally invasive posterior approach might be less exhausting for the patient. Moreover, debridement of the posterior intervertebral space and the epidural abscess might be easier via the posterior approach [5]. Independent of the surgical approach, usually autogenous bone grafts are considered to be the "gold standard" in spine reconstruction $[\mathbf{1 , 6 ]}$.

In this study we aim at introducing our experience with the treatment of spontaneous adult spondylodiscitis with interbody fusion using autogenous bone from decorticated spinous process supplanted with posterolateral transpedicular rod-screw fixation at the Neurosurgery Department of Benha University Hospital between January 2015 and November 2019.

\section{Patients and Methods}

Type of study: Retrospective cohort study.

Patients: Between January 2015 and November 2019, among 51 patients who were diagnosed with pyogenic thoracolumbar spondylodiscitis, 12 patients ( 8 males and 4 females) underwent curettage, drainage and interbody fusion using autogenous bone from the removed spinous process augmented with transpedicular rod-screw fixation.

\section{Pre-operative workup:}

In the absence of indications for surgical treatment, the conservative treatment was initialized. 
Conservative treatment includes immobilization of the involved spinal segment with rigid orthosis combined with antibiotic treatment. Conservative treatment should be abandoned if the symptoms persist or worse and if the inflammatory indicators and neuroradiological imaging do not provide signs of normalization. In these cases, surgical management should be considered.

Orthosis redistributes the load over the adjacent unaffected spinal segments, decreases stress and pressure in the affected area, decreases pain, and prevents segmental deformity. Furthermore, immobilization with orthosis avoids prolonged bed rest. We used orthosis for a period spanning 6-10 weeks [7].

Antibiotic treatment was delayed until samples for cultures are obtained. In case of negative cultures, an intravenous empiric wide-spectrum antibiotic therapy was recommended. Empirical antimicrobial therapy covered against Gram-positive organisms (staphylococcus including MRSA and streptococcus) and Gram-negative bacilli (Escherichia coli is the most represented). Accordingly, the recommended treatment included vancomycin and a third-or fourth-generation cephalosporin. In case of allergy or intolerance, alternative combinations included a quinolone.

Surgical treatment was generally recommended in case of neurological deficit, spinal instability, spinal deformity, sepsis, intra-canalicular lesion with mass effect, failure of conservative treatment including intractable pain, and patient's lack of compliance for conservative treatment. The goals of surgery are to remove the septic focus, identify the responsible microbial agent, stabilize the affected spinal segment, and promote bone fusion. Furthermore, it allows a rapid post-operative mobilization and a more reliable treatment of pseu- darthrosis and kyphotic deformity. Surgery is strongly indicated in presence of epidural abscess, even in the absence of neurological impairment.

\section{Surgical details:}

- General endotracheal anesthesia.

- Prone position and all pressure points were carefully padded.

- The whole back and upper buttocks was prepared and draped in the usual sterile manner.

- A skin incision was made over the posterior midline of the designated lumbar vertebrae level longitudinally.

- The dissection was progressed as a conventional method with level confirmation by flouroscopy until bilateral transverse processes were exposed partially as a landmark of the pedicle entry point.

- Next, the pedicle screws were inserted to healthy vertebrae.

- Spinolaminectomy flavectomy and/or pediculectomy can be applied.

- Complete discectomy, curretage of the disc space.

- Continous irrigation of the dic space with sterile normal saline until the fluid looked clear.

- Decorticated spinous process was inserted in the disc space (a single process in each space).

- Local administration of anti-infective agent (Gentamycin) [8].

Follow-up: The mean postoperative follow-up period was 24 months (range, 6 to 36 months). The follow-up visits were weekly in the first 3 months then monthly thereafter. In each visit, full neurological examination, laboratory investigations for the inflammatory markers and plain radiography were obtained.

\section{Results}

Table (1): Patients, criteria, pre-operative, operative and post-operative findings.

\begin{tabular}{|c|c|c|c|c|c|c|c|c|c|}
\hline Patient & Age & Sex & Complaint & Level & Pathogen & $\begin{array}{l}\text { Operative } \\
\text { time (min) }\end{array}$ & $\begin{array}{l}\text { Bleeding } \\
\quad(\mathrm{ml})\end{array}$ & $\begin{array}{l}\text { Post-op. } \\
\text { complications }\end{array}$ & $\begin{array}{l}\text { Post-operative } \\
\text { pain }\end{array}$ \\
\hline 1 & 27 & † & LBP & L4-5 & $-\mathrm{ve}$ & 140 & 500 & No & Improved \\
\hline 2 & 61 & $\Xi$ & LBP & L4-5 & $-\mathrm{ve}$ & 145 & 400 & No & Improved \\
\hline 3 & 45 & 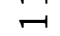 & LBP, SCIATICA & L4-5 & MRSA & 155 & 450 & No & Improved \\
\hline 4 & 52 & -1 & LBP, SCIATICA & L5-S 1 & $-\mathrm{ve}$ & 150 & 350 & No & Improved \\
\hline 5 & 56 & $=$ & LBP & L4-5 & $-\mathrm{ve}$ & 160 & 450 & No & Improved \\
\hline 6 & 30 & $\stackrel{+}{+}$ & LBP & L3-4 & MRSA & 155 & 250 & Fever & Improved \\
\hline 7 & 38 & t & LBP & L5-S 1 & $-\mathrm{ve}$ & 145 & 400 & No & Improved \\
\hline 8 & 71 & $\dot{\forall}$ & LBP, SCIATICA & L2-3 & $-\mathrm{ve}$ & 135 & 500 & No & The same \\
\hline 9 & 50 & 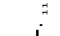 & LBP, SCIATICA & L5-S 1 & $-\mathrm{ve}$ & 140 & 500 & No & Improved \\
\hline 10 & 48 & 8 & LBP & L4-5 & MRSA & 150 & 450 & No & Improved \\
\hline 11 & 60 & $\nabla$ & LBP, SCIATICA & L4-5, L5-S 1 & $-\mathrm{ve}$ & 155 & 500 & No & Improved \\
\hline 12 & 42 & 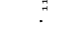 & LBP, SCIATICA & L4-5 & $-\mathrm{ve}$ & 145 & 300 & No & Improved \\
\hline
\end{tabular}


Patients: Among 51 patients who were diagnosed with pyogenic lumbar spondylodiscitis, 12 patients ( 8 males and 4 females) were included in this study their ages ranged between 27 and 71 years (mean 48.3).

Pre-operative data: 12 patients were included in this study. Eleven patients had single level discitis while only one patient had double level. L4-5 was the most affected level (7 patients) followed by L5-S 1 level.

One patient was re-admitted for administration of intravenous antibiotics after hospital discharge, because a fever had developed again. After an additional 2 weeks of parenteral antibiotics therapy, he left the hospital without any other pyretic event.

Clinical outcome: All patients, but one, showed improvement of their pre-operative pain and the level of inflammatory markers in the blood. This patient was diagnosed as having screw pull-out and needed surgical reinsertion with a larger screw.

Table (2): Improvement of levels of inflammatory mediators.

\begin{tabular}{lllll}
\hline \multirow{2}{*}{$\begin{array}{l}\text { Inflammatory } \\
\text { marker }\end{array}$} & $\begin{array}{c}\text { Pre- } \\
\text { operative } \\
\end{array}$ & \multicolumn{3}{c}{ Post-operative level } \\
\cline { 3 - 5 } & level & 3 weeks & 6 weeks & 12 weeks \\
\hline - C reactive protein & $47.8 \pm 6.1$ & $28.2 \pm$ & $19.6 \pm$ & $7 \pm$ \\
(N:0-8mg/L) & & 4.6 & 2.5 & 3.3 \\
- Erythrocyte & $115 \pm 23.8$ & $82 \pm$ & $75 \pm$ & $55 \pm$ \\
sedimentation rate & & 11.9 & 21.1 & 8.4 \\
( N:0-35mm/h) & & & & \\
- White blood cells & $9.8 \pm 2.1$ & $9.1 \pm$ & $8.2 \pm$ & $6.8 \pm$ \\
$\left(\mathrm{N}: 4-11 \mathrm{X} \mathrm{10} 10^{3} / \mathrm{uL}\right)$ & & 1.8 & 2.4 & 3.6 \\
\hline
\end{tabular}

Radiological outcome: Radiologically, all patients reached the spontaneous fusion between the infected vertebrae and only one patient had one screw pulled-out and needed further re-surgery.

\section{Illustrative cases:}

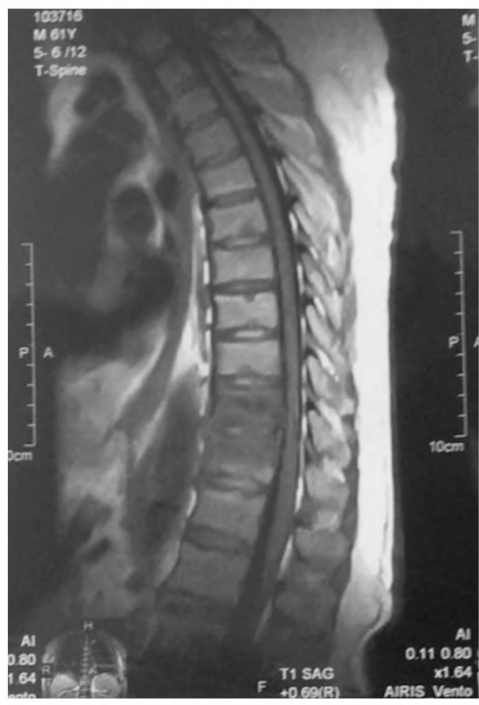

(A)

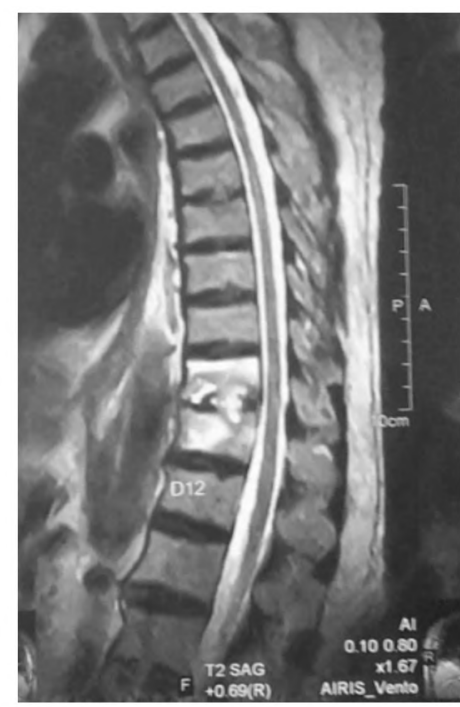

(B)

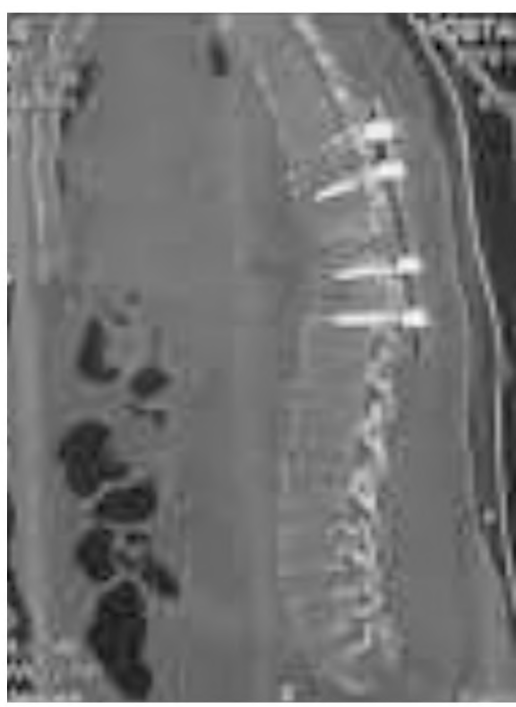

(C)

Fig. (1): Pre-operative MRI T1 (A) \& T2 (B) and post-operative sagittal CT scan.

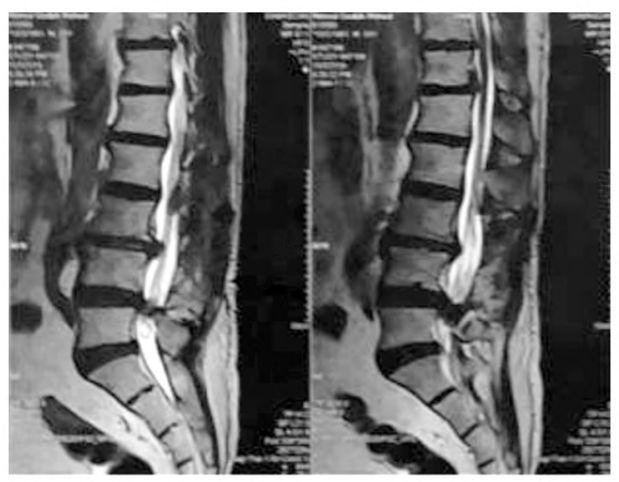

(A)

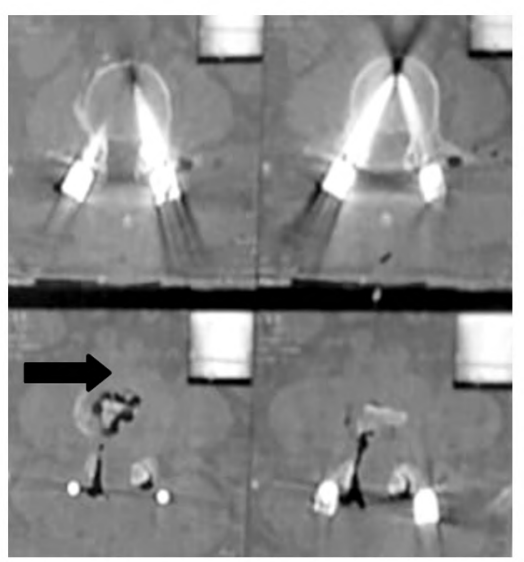

(B)

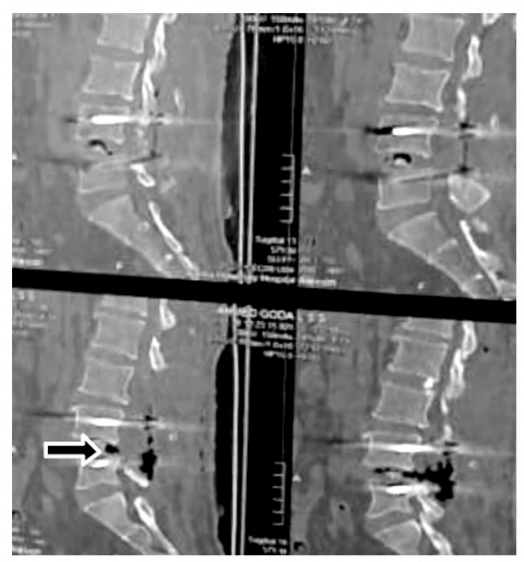

(C)

Fig. (2): Pre-operative MRI T2 (A) Post-operative Axial CT (B) and post-operative sagittal CT (C) Showing the implanted scrows and and the sapplanted bone fragment (arrow). 


\section{Discussion}

Spinal infection accounts for $2 \%-7 \%$ of all cases of musculoskeletal infections. During the last few decades, infections of the spine have been diagnosed with increasing frequency. The clinical features of spinal infections vary between longlasting, localized and slowly progressive backache and nearly acute, septic and life-threatening courses with severe back pain and rapidly progressive neurological deficits [9].

Hematogenous spinal infections frequently present as spondylodiscitis, leading to neurological deficits due to secondary epidural abscesses in a considerable number of cases. Many patients with hematogenous spinal infections suffer from multiple predisposing conditions, and preceding non-spinal infections are common. Staphylococcus aureus is the predominant causative organism the early recognition of pyogenic spinal infections is very important, because specific treatment can lead to a significant improvement of morbidity and mortality. The majority of spondylodiscitis without neurological deficits or severe progressive symptoms respond well to conservative treatment by intravenous antibiotics and spinal external immobilization. Surgical decompression is mandatory in the presence or development of significant neurological deficits [9].

Surgical treatment was generally recommended in case of neurological deficit, spinal instability, spinal deformity, sepsis, intra-canalicular lesion with mass effect, failure of conservative treatment including intractable pain, and patient's lack of compliance for conservative treatment [10]. Until now, the role of spinal instrumentation in the presence of infection has been hardly discussed. In recent years direct spinal fixation following the debridement of the lesion of tuberculous spondylitis and pyogenic discitis has been conducted; this was following the knowledge in osteomyelitis of providing stability to long bones using metal implants being effective in inflammation control even when metallic or cement implants were placed in an infected area [11]. The goals of surgery are to remove the septic focus, identify the responsible microbial agent, stabilize the affected spinal segment, and promote bone fusion [12]. Furthermore, it allows a rapid postoperative mobilization and a more reliable treatment of pseudarthrosis and kyphotic deformity. Surgery is strongly indicated in presence of epidural abscess, even in the absence of neurological impairment [10].
More recently, Mohamed et al., [11] showed that long posterior pedicle screws fixation combined with aggressive antibiotic therapy resulted in resolution of spinal infection in 15 patients. In these two series, no relapse of infection was observed after surgery with titanium implants. Also, demonstrated that stabilizing the spine with pedicle screws and titanium mesh prevented the deformity in patients with tuberculous spondylitis and the metallic implants did not prohibit infection control [11].

Spinal cord compression is a surgical emergency. The reported outcomes are worse if emergency surgery is performed after 24-36h upon the onset of the neurological deficit [13]. The recommendations for the surgical treatment are still controversial. The standard procedure involves debridement of the septic focus, span interposition, and then instrumented stabilization [14]. Many surgical approaches have been proposed, but in the absence of strict guidelines, the treatment depends on experience/preference of the surgeon [15]

Traditionally, anterior/posterior combined approach was preferred for spontaneous spondylodiscitis $[9,16]$ however some authors prefer using the posterior approach alone $[17,18]$.

There is unanimity of opinion that a sufficient amount of bone graft and a good environment of the grafting site are crucial to completing a solid fusion. Compared with the posterolateral technique, interbody fusion has several advantages that include immediate anterior column load shearing, large surface area for fusion, and bone graft subjected to compressive loads.

Rath et al., [19] compared retrospectively the results of debridement and posterior internal fixation. A high percentage of the patients suffered, like those in the present study, from associated illnesses and were in a reduced general condition. The overall good outcome suggested that a posterior approach in a single-staged procedure using a transpedicular screw-rod system, which could be left in place, and autologous bone is nearly always sufficient and does not bear a higher risk of persistence or recurrence of the infection. The study combined data of post procedural and spontaneous spondylodiscitis and of tuberculous and nonspecific infections as well as thoracic and lumbar operative interventions. The mean age of the patients was somewhat lower than in this present study [19].

In this study, marked clinical and radiological outcome was noted (11 out of 12 patients, $91.7 \%$ ). 
It has been reported that clinical and radiological outcomes were poor if anterior debridement and reconstruction of the anterior column were not performed [20]. However, in this current procedure, the remaining normal anatomical structures were strong enough that no additional anterior column support was necessary.

\section{Conclusions:}

From the results of this study we can conclude that lumbar interbody fusion using autogenous bone from decorticated spinous process supplanted with posterolateraltranspedicular rod-screw fixation represents a reasonable substitute to the traditional anterior curettage, stabilization with additional posterior rod-screw fixation for the treatment of spontaneous lumbar spondylodiscitis.

\section{Limitation of the study:}

The small number of patients in our series may limits statistics, but overall it is still could a descriptive study. We still recommend a comparative study between patients that had surgery for RLDP with and without fusion would be more beneficial.

Financial support \& sponsorship:

Nil.

\section{Conflicts of interest:}

There are no conflicts of interest.

\section{References}

1- BOSTELMANN R., STEIGER H.J. and SCHOLZ A.O.: First report on treating spontaneous infectious spondylodiscitis of lumbar spine with posterior debridement, posterior instrumentation and an injectable calcium sulfate/hydroxyapatite composite eluting gentamicin: A case report. J. Med. Case Rep., 10: 349, 2016.

2- CORNETT C.A., VINCENT S.A., CROW J., et al.: Bacterial spine infections in adults: Evaluation and management. J. Am. Acad. Orthop. Surg., 24: 11-8, 2016.

3- GONZALVO A., ABDULLA I., RIAZI A., et al.: Single level/single-stage debridement and posterior instrumented fusion in the treatment of spontaneous pyogenic osteomyelitis/discitis: Long-term functional outcome and healthrelated quality of life. J. Spinal Disord. Tech., 24: 110$5,2011$.

4- BERBARI E.F., KANJ S.S., KOWALSKI T.J., et al.: Executive Summary: 2015 Infectious Diseases Society of America (IDSA) Clinical Practice Guidelines for the diagnosis and treatment of native vertebral osteomyelitis in adults. Clin. Infect. Dis., 61: 859-63, 2015.

5- MANN S., SCHÜTZE M., SOLA S., et al.: Nonspecific pyogenic spondylodiscitis: Clinical manifestations, surgica treatment, and outcome in 24 patients. Neurosurg. Focus, 17: E3, 2004.
6- MYEROFF C. and ARCHDEACON M.: Autogenous bone graft: Donor sites and techniques. J. Bone Joint Surg. Am., 93: 2227-36, 2011.

7- BETTINI N., GIRARDO M., DEMA E., et al.: Evaluation of conservative treatment of non specific spondylodiscitis. Eur. Spine J., 18 (Suppl 1): 143-50, 2009.

8- SHIBAN E., JANSSEN I., Da CUNHA P.R., et al.: Safety and efficacy of polyetheretherketone (PEEK) cages in combination with posterior pedicel screw fixation in pyogenic spinal infection. Acta Neurochir (Wien), 158: 1851-7, 2016

9- QINONES-HINOJOSA A., JUN P., JACOBS R., ROSENBERG W.S. and WEINSTEIN P.R.: General principles in the medical and surgical management of spinal infections: A multidisciplinary approach. Neurosurg. Focus, 17: E1, $1-15,2004$.

10- GOULIOURIS T., ALIYU S.H. and BROWN N.M.: Spondylodiscitis: Update on diagnosis and management. J. Antimicrob. Chemother., 65 (Suppl 3): iii11-24, 2010.

11- MOHAMED A.S., YOO J., HART R., et al.: Posterior fixation without debridement for vertebral body osteomyelitis and discitis. Neurosurg. Focus, 37: E6, 2014.

12- KAPSALAKI E., GATSELIS N., STEFOS A., et al.: Spontaneous spondylodiscitis: Presentation, risk factors, diagnosis, management, and outcome. Int. J. Infect. Dis., 13: 564-9, 2009.

13- DAROUICHE R.O.: Spinal epidural abscess. N. Engl. J. Med., 355: 2012-20, 2006.

14- SOBOTTKE R., SEIFERT H., FÄTKENHEUER G., et al.: Current diagnosis and treatment of spondylodiscitis. Dtsch. Arztebl. Int., 105: 181-7, 2008.

15- SUR A., TSANG K., BROWN M. and TZERAKIS N.: Management of adult spontaneous spondylodiscitis and its rising incidence. Ann. R. Coll. Surg. Engl., 97: 451$5,2015$.

16- OZALAY M., SAHIN O., DERINCEK A., et al.: Nontuberculous thoracic and lumbar spondylodiscitis: Singlestage anterior debridement and reconstruction, combined with posterior instrumentation and grafting. Acta Orthop. Belg., 76: 100-6, 2010.

17- GHOBRIAL G.M., AL-SAIEGH F., FRANCO D., et al.: Lateral lumbar retroperitoneal transpsoas approach in the setting of spondylodiscitis: A technical note. J. Clin. Neurosci., 39: 193-8, 2017.

18-ZHANG L., CAI W.H., HUANG B., CHEN L.W., ZHANG N. and NI B.: Single-stage posterior debridement and single-level instrumented fusion for spontaneous infectious spondylodiscitis of the lumbar spine. Acta Orthop. Belg., 77: 816-22, 2011.

19- RATH S.A., NEFF U., SCHNEIDER O. and RICHTER H.P.: Neurosurgical management of thoracic and lumbar vertebral osteomyelitis and discitis in adults: A review in 43 consecutive surgically treated patients. Neurosurgery, 38: 933-8, 1996.

20- CHEN Y.C., CHANG M.C., WANG S.T., et al.: One-stage posterior surgery for treatment of advanced spinal tuberculosis. J. Chin. Med. Assoc., 66 (7): 411-7, 2003. 


\section{علاج الإلتهاب الفقرى الصدرى القطنى للبالغين

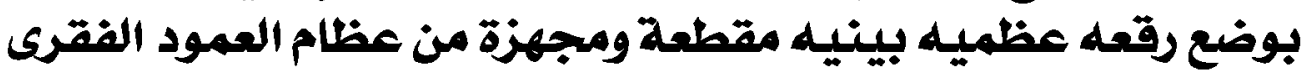

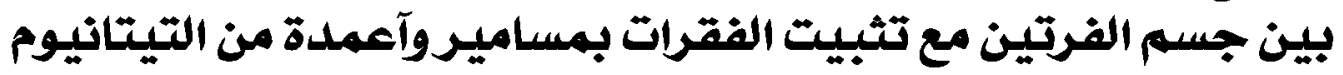

خلفية علمية: إلتهاب الفقار العفوى عفوية، على الرغم من ندرته، ولكن يحمل خطر التسبب في مضاعفات عصبية.

هدف الدراسة: نحن نهدف إلى تقييم تجريتنا في علاج إلتهاب الفقار الصديدى للى البالغين مع إدماج رقعه عظمية من العمود الفقرى

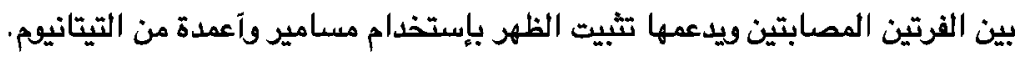

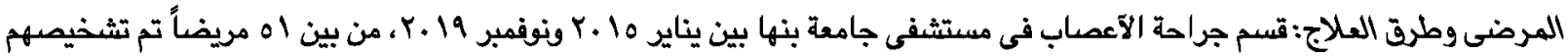

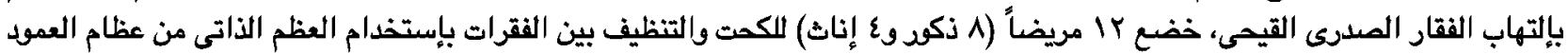
الفقرى (الشواكه العظميه) التى تمت إزالتها مع تثبيث الفقرات بإستخدام مسامير وآعمدة من التيتانيوم.

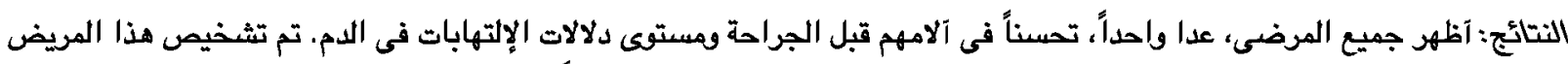

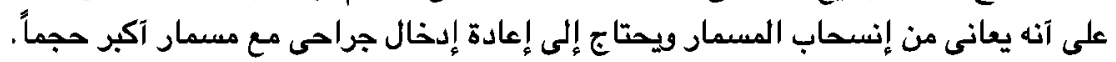

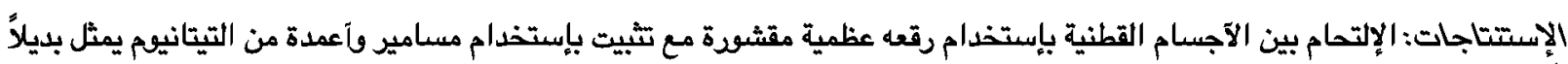

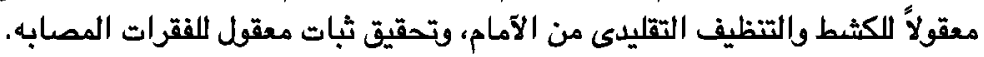

